\title{
Evidence for Rapoport's rule and latitudinal patterns in the global distribution and diversity of alien bird species
}

\author{
Ellie E. Dyer ${ }^{1}$ (D) | David W. Redding ${ }^{1}$ (D) | Phillip Cassey ${ }^{2}$ (D) | Ben Collen ${ }^{1 *}$ (D) \\ Tim M. Blackburn ${ }^{1,3,4}$
}

\footnotetext{
${ }^{1}$ Centre for Biodiversity and Environment Research, Department of Genetics, Evolution and Environment, University College London, London, UK

${ }^{2}$ Centre for Conservation Science and Technology, and School of Biological Sciences, University of Adelaide, Adelaide, SA, Australia

${ }^{3}$ Institute of Zoology, Zoological Society of London, London, UK

${ }^{4}$ Centre for Invasion Biology, Department of Botany and Zoology, Stellenbosch University, Stellenbosch, South Africa

\section{Correspondence and Environment Research, Department of Genetics, Evolution and Environment, University College London, London, UK. \\ Email: t.blackburn@ucl.ac.uk}

Tim M. Blackburn, Centre for Biodiversity
}

\section{Funding information}

UCL IMPACT Studentship, Grant/Award Number: 10989; Leverhulme Trust, Grant/ Award Number: RF/2/RFG/2010/0016 and RPG-2015-392; King Saud University

Handling Editor: Werner Ulrich

\begin{abstract}
Aim: To quantify global latitudinal patterns in the distributions of alien bird species to assess whether these species conform to Rapoport's rule (i.e. show a positive latitudinal gradient in latitudinal range extent), and to test whether where species are introduced, and where species fail to establish, may help to drive observed patterns. Location: Global.

Taxon: Birds (group Aves).

Methods: Data on locations of introduction and establishment for 355 species with established alien populations were combined with data on native range extents (measured in $5^{\circ}$ bands of latitude). Relationships between (a) latitude and introduced and established alien species richness, and (b) latitude and introduced and established alien range extent, were plotted. Linear regressions and paired $t$-tests were used to compare latitudinal range extents, midpoints, and limits of each species in its introduced alien range, established alien range and native range.

Results: Latitudes that have more established alien bird species also have had more species introduced in total. The mean total latitudinal extents (i.e. geographic range size) of established alien bird species increase with latitude poleward of the tropics, consistent with Rapoport's rule, but are smaller in the tropics. This pattern is weaker in the range sizes of native bird species. Alien bird species are more likely to be introduced within the latitudinal confines of their native ranges, and are more likely to contract away from the more extreme latitudes to which they were introduced. Alien bird species are in general more likely to have established populations nearer the equator. Main conclusions: Including data on locations of introduction in addition to established distributions enables us to determine the extent to which large-scale alien species distributions are determined by anthropogenic or natural processes. Latitudinal patterns in range extent (Rapoport's rule) and species richness in alien birds are largely a consequence of where species have been introduced, and hence are unlikely to be informative of equivalent patterns in native species.
\end{abstract}

\section{KEYWORDS}

alien species, birds, geographic range size, latitude, Rapoport's rule, species distribution, species richness 


\section{1 | INTRODUCTION}

It has long been recognized that biodiversity displays systematic patterns of spatial variation (Arrhenius, 1921; Dobzhansky, 1950; Fischer, 1960; Pianka, 1966; Rapoport, 1982; von Humboldt, 1850). Many of the best studied associations relate to latitude. For example, species richness tends to be negatively correlated with latitude, decreasing from the tropics to the poles (Rohde, 1992). The reason for this association is yet to be determined, but is thought to be due to a combination of the effects of availability of energy or temperature on population dynamics (Davies et al., 2007; Gillman et al., 2015; Hawkins et al., 2003; Rohde, 1992; Whittaker, Willis, \& Field, 2003), coupled with the time available for the process of diversification to occur (Dowle, Morgan-Richards, \& Trewick, 2013; Gillman \& Wright, 2014; Pianka, 1966; Rohde, 1992; Wright, Gillman, Ross, \& Keeling, 2010; Wright, Keeling, \& Gillman, 2006). Conversely, native geographic range size in terrestrial systems tends to be positively correlated with latitude, a phenomenon known as Rapoport's rule (Rapoport, 1982; Stevens, 1989), such that as the number of species inhabiting a latitude decreases, the extent of their distributions increase, on average. The generality of this rule has been much debated in the literature, and in the marine environment bivalves actually demonstrate an inverse relationship between range size and latitude, in opposition to Rapoport's rule (Tomašových, Jablonski, Berke, Krug, \& Valentine, 2015). A range of hypotheses have been proposed to explain the pattern where present (see Rohde, 1992). Candidate explanations include climatic variability (Dobzhansky, 1950; France, 1992; Stevens, 1989), climatic extremes (Pither, 2003), competition (Pianka, 1989; Stevens, 1996), biogeographical boundaries (Blackburn \& Gaston, 1996; Roy, Jablonski, \& Valentine, 1994; Smith, May, \& Harvey, 1994) and differential extinction or glacial history (Araújo et al., 2008; Brown, 1995; Jansson, 2003).

Differentiating between the hypotheses put forward to explain latitudinal patterns is difficult. This is because there is a limited quantity of suitable data, manipulative experiments are almost impossible to undertake and few replicates exist at the large scales over which these patterns are expressed. To address these issues, some authors have turned to alien species introductions as a form of natural experiment to test the mechanisms driving latitudinal patterns (e.g. Blackburn, Redding, \& Dyer, 2018; Blanchet et al., 2010; Guo, Sax, Qian, \& Early, 2012; Sax, 2001). An alien species is one which has been introduced by a human vector beyond the limits of its native range, either accidentally or on purpose (Blackburn, Lockwood, \& Cassey, 2009). Similarities and differences in the patterns expressed by alien and native species may be informative about the drivers of patterns in the latter group. Birds are a suitable alien taxon with which to explore these patterns, as they have been introduced worldwide to all ice-free latitudes (Dyer, Cassey, et al., 2017), and there is extensive information available on their native (del Hoyo, Elliott, Sargatal, Christie, \& de Juana, 2018; Orme et al., 2006), and alien distributions (Dyer, Redding, \& Blackburn, 2017; Lever, 2005; Long, 1981).
There is evidence that alien bird species richness varies with latitude, as is the case for native bird species. Sax (2001) showed that established alien bird species richness on continents (excluding Australia) increases from the poles to the edges of the tropics in both the Northern and Southern Hemispheres, but attains only relatively low levels throughout the tropics. He argued that in the temperate zone, this was due to the primarily environmental (abiotic) determinants of native species richness also impacting upon the richness of alien bird species. In the tropics, he postulated that the low alien bird richness may be a result of biotic resistance from the high diversity of native species found there (Sax, 2001). However, it has since been postulated that latitudinal gradients in alien species richness, or geographic range extent, may arise as a result of human actions in introducing species (Dyer, Cassey, et al., 2017), rather than the abiotic or biotic effects that underlie these patterns in native species (Pyšek et al., 2010).

Sax (2001) also demonstrated that the latitudinal range extents of established alien bird species introduced to North America increased with latitude north of the tropical zone, in concordance with Rapoport's rule, but were consistently large in the tropics, similar in extent to those recorded at high North American latitudes. He used variations in the upper (i.e. poleward) and lower (equatorward) latitudinal range limits of the native and alien distributions of these species to assess likely causes, arguing that established alien latitudinal range extents could be explained in terms of the response of species to contemporary ecological conditions. Sax (2001) found that whilst the poleward latitudes in the native and alien ranges of bird species tended to be correlated, species were more likely to exceed their natural poleward latitude range limits than their natural equatorward latitude range limits in their alien range.

Subsequently, Guo et al. (2012) found similar patterns to Sax (2001) in alien bird species, with positive correlations between the latitudes occupied by a species' established alien and native ranges, with relatively more alien species occurring poleward in relation to their native ranges, and fewer occurring equatorward. They showed that although a small fraction of alien species occurred beyond both their upper and lower native latitudinal limits, most had not yet reached the latitudinal extent observed in their native range. They proposed that these shifts may be due to climate change, historical limitations on native ranges, greater biotic resistance at lower latitudes and the impacts of humans on species distributions (Guo et al., 2012).

The geographic patterns described by Sax (2001) and Guo et al. (2012) assume that the opportunity for biological invasion is similar across latitudes. Yet, these analyses only examine those species with established distributions: they do not fully consider the effects of where species have been introduced, and where introduced species have succeeded or failed. Their transitory nature means that data on failed introductions are harder to obtain than data on successfully established species (Blackburn et al., 2009; Dyer, Cassey, et al., 2017; Pyšek et al., 2010), and therefore patterns in alien species latitudinal distributions have generally been described without fully taking them into account (although see 
Blackburn et al., 2018). Sax (2001) rejected an association between the distribution of species introductions and alien species richness, arguing that the latitudinal pattern of introduction events for alien birds in North America did not match the latitudinal pattern of established species richness. However, Dyer, Cassey, et al. (2017) showed that alien bird species richness worldwide was strongly related to the number of bird species introduced to an area ('colonisation pressure', see also Blackburn et al., 2009). Guo et al. (2012) suggested that biases in the location of introductions may explain the latitudinal patterns that they found, but did not test this.

In this paper, we examine the latitudinal patterns in the richness and geographical extents of alien bird distributions in relation to their native ranges at the global scale, and explore whether where species are introduced, and where species fail to establish, may help to drive these observed patterns. Using the GAVIA database (Dyer, Redding, et al., 2017), we test the relationships between latitude and introduced and established alien species richness, and between latitude and introduced and established alien range extent at the global scale. We compare the latitudinal range extent, latitudinal midpoint, and the equatorward (lowest) and poleward (highest) latitudinal limits of each species in its introduced and established alien range and in its native range. Incorporating data on locations of introduction in addition to established distributions enables us to ascertain whether species introduced beyond the latitudinal limits of their native ranges are more likely to succeed or fail. This allows us to explore the extent to which latitudinal patterns in range extent and species richness may be a consequence of human actions in introducing species versus abiotic or biotic environmental effects, and hence the extent to which latitudinal patterns in alien species are informative of equivalent patterns in native species.

\section{2 | MATERIALS AND METHODS}

\section{1 | Data}

Introduction data for 711 alien bird species were extracted from the GAVIA database (Dyer, Redding, et al., 2017). This represents the number of alien bird species introduced globally (i.e. species which have been recorded outside of their native range), regardless of outcome, for which there is sufficient information to enable a range map to be created specifically for the area where the species were initially introduced. Of these species, 355 had at least one successfully established population (i.e. the species has formed self-sustaining populations in the area of introduction) for which a range map existed. For more detailed information regarding the inclusion criterion for these species, and how the range maps were created, see Dyer, Redding, et al. (2017). Native range metrics for the 355 established species were calculated using native breeding range information obtained from the $\mathrm{ADHoC}$ (Avian Diversity Hotspots Consortium) database, first published by Orme et al. (2005).
Using ESRI ArcGIS version 10.6 (2018), the native and alien range maps were intersected with a shapefile delineating $5^{\circ}$ bands of latitude (following Sax, 2001). For each of these $5^{\circ}$ latitudinal bands, four metrics were calculated:

1. The number of established alien species was calculated by counting the number of alien species with an established range within or overlapping each band.

2. The number of introduced alien species was calculated by counting the number of alien species introduced within each band. For both 1) and 2), if the same species was present on multiple continents, at the same band of latitude, it was only counted once for that band.

3. The mean latitudinal range extent of the established range (a measure of geographic range size) for all the established alien species in each band was extracted. This was calculated by summing the number of $5^{\circ}$ bands of latitude between (and including) the northernmost and southernmost point of the range of each established alien species within each band, regardless of whether or not it crossed the equator, to produce a maximum latitudinal range extent. For example, if the northernmost and southernmost points of a species range covered four $5^{\circ}$ bands of latitude, then its range extent would be recorded as $20^{\circ}$. The range extents were then averaged across all the species present in each band.

4. The mean latitudinal range extent of the introduction records for each band was extracted. This was calculated by summing the number of $5^{\circ}$ bands of latitude between (and including) the northernmost and southernmost point at which each alien species had been introduced, regardless of whether or not it crossed the equator, to produce a maximum latitudinal range extent. As above, if the northernmost and southernmost points of a species' introduced range covered four $5^{\circ}$ bands of latitude, then its range extent would be recorded as $20^{\circ}$. The introduced range extents were then averaged across all the species present in each band.

For both 3) and 4) the actual range extent may be disconnected - the species may not be introduced or established in every band between the northernmost and southernmost point, yet the range extent is calculated as the total number of bands between (and including) the northernmost and southernmost points. We took this approach because geographic gradients mean that the extremes of abiotic and biotic conditions encountered by an alien species, which are likely to be factors that will have an impact on whether they establish at a latitude, are likely to be expressed at the absolute upper and lower limits of its distribution. Whether the rest of their range is connected or disconnected within that gradient is less important, given that intermediate biotic and abiotic conditions will be experienced at intermediate latitudes. For around seven of the 355 species, introduced and established ranges are highly disconnected, such that the species was recorded at high latitudes north and south of the equator, but not in between. While these species do not experience a wide range of conditions across their alien latitudinal distribution, they are a small proportion of our total sample $(<2 \%)$ and do not affect our conclusions. 
Three of the most poleward latitudinal bands were excluded from the analysis due to low sample size: the band between 65 and $70^{\circ} \mathrm{N}$ in which zero species were introduced but three species are now established (due to spread), the band between 70 and $75^{\circ} \mathrm{N}$ in which zero species were introduced and two species are now established, and the band between 55 and $60^{\circ} \mathrm{S}$ which had two species both introduced and established. This left 13 latitudinal bands in the Northern Hemisphere, from 0 to $65^{\circ} \mathrm{N}$ and 11 latitudinal bands in the Southern Hemisphere, from 0 to $55^{\circ} \mathrm{S}$.

For each species, we extracted the following information from their native range, introduced alien range and established alien range:

5. The absolute lowest (equatorward) latitudinal range limit was recorded for each species for its native range, introduced alien range and established alien range. This was calculated irrespective of the hemisphere in which a species occurred. For example, if a species occurred only in the $5^{\circ}$ band spanning $10-15^{\circ} \mathrm{N}$, then its equatorward latitudinal range limit would be $10^{\circ}$, and likewise if it occurred only in the $5^{\circ}$ band spanning $10-15^{\circ} \mathrm{S}$. If a species occurred in different locations, only a single global equatorward latitudinal limit was recorded. For species present in separate populations in both the Northern and Southern Hemisphere, the equatorward latitude was recorded as the lowest latitudinal range limit of the population closest to the equator. If a species' distribution intersects $0-5^{\circ} \mathrm{N}$ or $S$ then its equatorward latitude was recorded as $0^{\circ}$.

6. The absolute highest (poleward) latitudinal range limit was recorded for each species in its native range, introduced alien range and established alien range. Again, this was calculated irrespective of the hemisphere in which a species occurred, such that the $5^{\circ}$ band range boundary closest to the poles was 'highest'. For example, for a species occurring only in the $5^{\circ}$ band that spanned $10-15^{\circ} \mathrm{N}$, then its poleward latitudinal range limit would be $15^{\circ}$. If a species occurred in different locations, only a single global poleward latitudinal limit was recorded. For species present in separate populations in both hemispheres, the poleward latitude was recorded as the highest latitudinal range limit of the population closest to the poles.

7. The latitudinal midpoint was recorded for each species for its native range, introduced alien range and established alien range. Latitudinal midpoint values were calculated as the point equidistant between a species' equatorward and poleward latitudinal range limits (values from 5 and 6 above). If a species' distribution spanned the equator then its latitudinal midpoint value was calculated relative to the single hemisphere where it had the largest latitudinal extent, such that the value equals the average of its lowest (i.e. $0^{\circ}$ ) and its highest latitudinal range limits.

8. The absolute latitudinal range extent for each species was calculated by subtracting the equatorward latitudinal range limit from the poleward latitudinal limit (values from 5 and 6 above) of each species' native range, introduced alien range and established alien range, even if the range was disconnected.

\section{2 | Statistical analysis}

\subsection{1 | Latitudinal band-level analyses}

Ordinary least squares regressions were used to assess the relationship between latitude and: (a) the mean latitudinal extent of the established range for species present within each $5^{\circ}$ band (termed Stevens' method; Stevens, 1989); (b) the mean latitudinal extent for the introduced range for species introduced within each $5^{\circ}$ band; (c) the number of alien bird species established within each $5^{\circ}$ band; (d) the number of alien bird species introduced within each $5^{\circ}$ band; and (e) the number of alien bird species that have successfully established divided by the total number introduced, within each $5^{\circ}$ band. A quadratic term for latitude was included where the relationships were nonlinear.

\subsection{2 | Species-level analyses}

Paired $t$-tests and Pearson's rank correlations were used to examine the relationships between four metrics of each species' native range, introduced alien range and established alien range. These were the equatorward latitudinal limit, latitudinal midpoint, poleward latitudinal limit and absolute latitudinal extent. All analyses were conducted in the R software environment for statistical and graphical computing, version 3.4.3 (R Core Team, 2018). The R package Plotrix (Lemon, 2006) was used within the figures.

\section{3 | RESULTS}

Alien bird introductions have occurred at the majority of latitudes with ice-free land. The pattern of variation is multimodal, with the greatest peaks in both the number of species introduced and the number of species established between 15 and $30^{\circ} \mathrm{N}$, but with further smaller peaks between $0-5^{\circ} \mathrm{N}, 15-25^{\circ} \mathrm{S}$ and $30-45^{\circ} \mathrm{S}$ (Figure 1a,b).

\section{1 | Latitudinal band-level analyses}

The number of introduced alien bird species varies with latitude in both the Northern and Southern Hemispheres (Figure 1a,b). There is an $n$-shaped relationship between introduced richness and latitude in the Northern Hemisphere, where introduced alien bird richness peaks at the Tropic of Cancer, and decreases towards the poles and the equator ([latitude slope \pm standard error; latitude ${ }^{\wedge} 2$ slope \pm standard error] $\left.8.84 \pm 3.89 ;-0.16 \pm 0.06 ; r^{2}=.42, p<.05\right)$. A similar trend exists in the Southern Hemisphere, albeit not formally significant $\left(6.34 \pm 2.79 ;-0.12 \pm 0.05 ; r^{2}=.30 ; p=.1\right)$. The relationship between latitude and the number of established alien species is similar (Northern Hemisphere: $3.79 \pm 1.86 ;-0.07 \pm 0.03 ; r^{2}=.44$, $p<.05$. Southern Hemisphere: $2.10 \pm 0.93 ;-0.04 \pm 0.02 ; r^{2}=.27$; 
FIGURE 1 The relationships between latitude and the number of alien bird species that have been introduced (crosses) and that are established (dots) in (a) the Northern and (b) Southern Hemispheres; the number of established species relative to the number introduced in (c) the Northern and (d) Southern Hemispheres; and mean total latitudinal range extent of the alien species that have been introduced (crosses) and that are established (dots) in (e) the Northern and (f) Southern Hemispheres. Latitude is measured in $5^{\circ}$ latitudinal bands. The vertical dotted lines indicate the Tropic of Cancer or Capricorn, dividing tropical and temperate latitudes. The dashed lines represent the coefficients from the fitted ordinary least squares models (slope estimate) for the introduced species, the solid lines represent the same for the established species. $n=355$ (a)

Northern Hemisphere
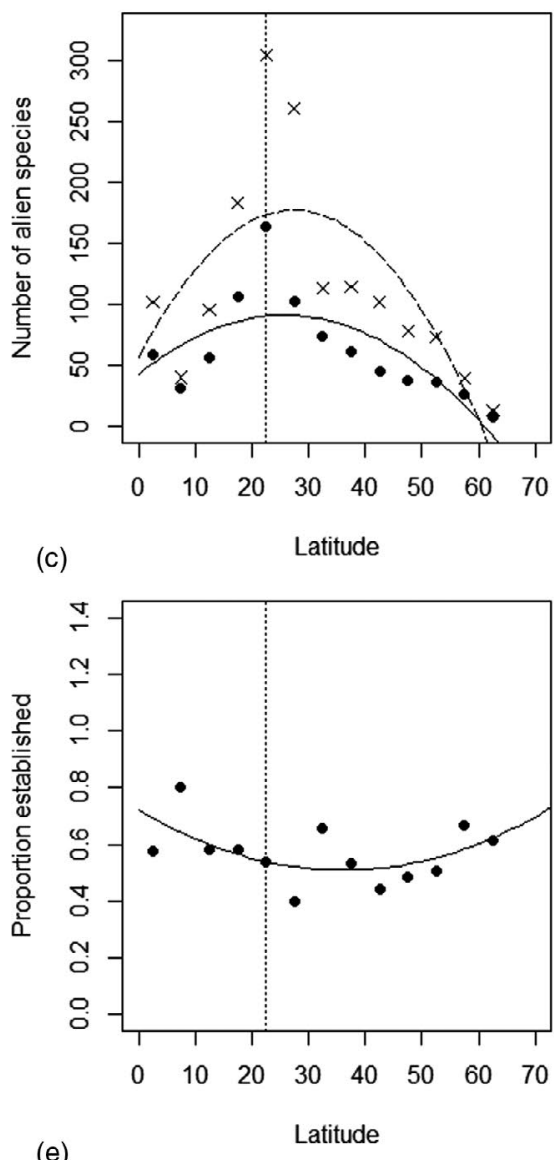

(e)

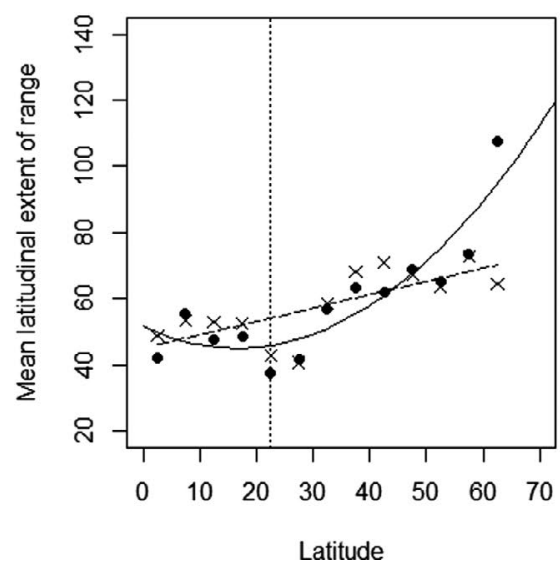

(b)

Southern Hemisphere

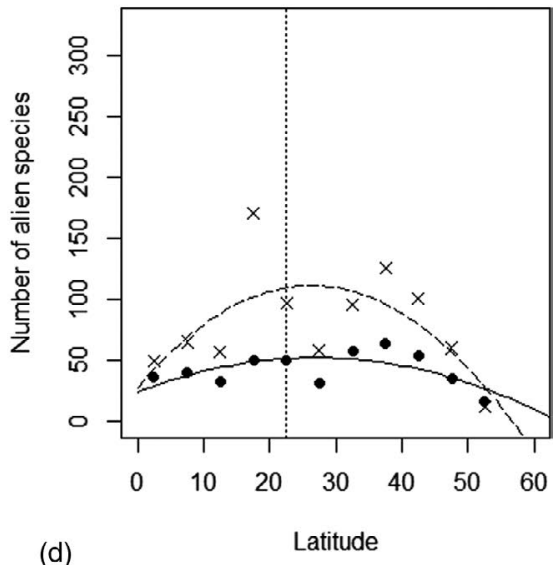

(d)

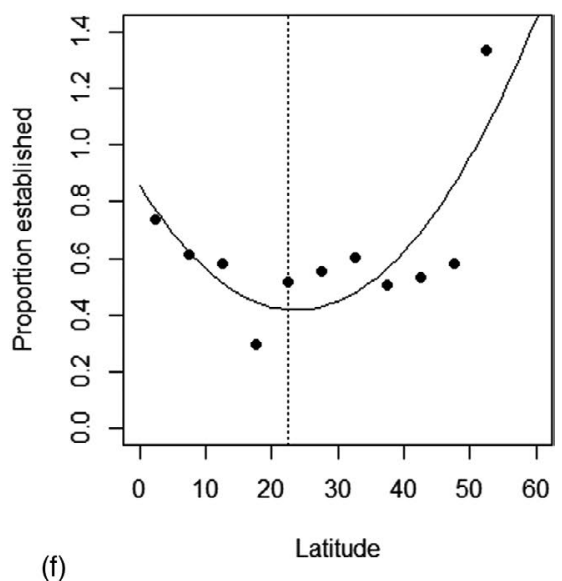

(f)

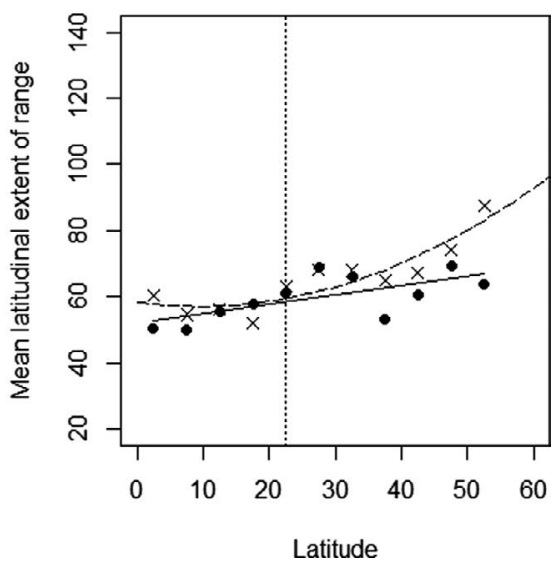

$p=.1$ ), with peaks that mirror those of introduced alien species richness (Figure 1a,b).

In the Northern Hemisphere there is no relationship between latitude and the number of established species relative to the number introduced (Figure 1c; [latitude slope \pm standard error; latitude ${ }^{\wedge} 2$ slope \pm standard error] $-0.01 \pm 0.006 ; 0.0001 \pm 0.0001 ; r^{2}=.16$; $p=.1)$. In the Southern Hemisphere there is a $\mathrm{U}$-shaped relationship, with the number of established species relative to the number introduced, lowest near the Tropic of Capricorn (Figure 1d; $-0.04 \pm 0.01$; $\left.0.001 \pm 0.0002 ; r^{2}=.54, p<.05\right)$.

The mean introduced alien range extent within each $5^{\circ}$ latitudinal band is positively correlated with latitude (Figure 1e,f).
The relationship is linear in the Northern Hemisphere (Figure 1e; [latitude slope \pm standard error]: $0.40 \pm 0.11 ; r^{2}=.49, p<.01$ ) but curved upwards in the Southern Hemisphere, where a quadratic term for latitude was included in the best model (Figure 1f; [latitude slope \pm standard error; latitude^ 2 slope \pm standard error] $-0.27 \pm 0.37 ; 0.01 \pm 0.006 ; r^{2}=.77, p<.01$ ).

The mean established alien range extent within each $5^{\circ}$ latitudinal band is also positively correlated with latitude (Figure 1e,f). In contrast to the introduced alien range extent, this relationship is curvilinear in the Northern Hemisphere (Figure 1e; [latitude slope \pm standard error; latitude ${ }^{\wedge} 2$ slope \pm standard error]: $-0.79 \pm 0.52 ; 0.02 \pm 0.01 ; r^{2}=.78, p<.001$ ) and linear in the Southern 
Hemisphere (Figure 1f; [latitude slope \pm standard error] $0.29 \pm 0.10$ $\left.r^{2}=.41, p<.05\right)$. However, it should be noted that this pattern is somewhat driven by a small number of wide-ranging species established at high latitudes in the Northern Hemisphere, as without this point the patterns of introduced and established alien range extents are very similar.

\section{2 | Species-level analyses}

In general, alien species are more likely to be introduced towards the higher poleward latitudes of their native ranges than the lower equatorward latitudes, and subsequently have smaller absolute latitudinal extents in the introduced range compared to the native range. Comparisons of individual species latitudinal distributions showed that the equatorward latitudinal limits, poleward latitudinal limits, mid-latitudes and absolute latitudinal extents of species' native and introduced ranges are positively correlated in each case (Table 1a, Figure $2 a-d$ ): species with their poleward native latitudinal limits at higher latitudes also tend to have their poleward introduced latitudinal limits at higher latitudes, and so on. However, paired $t$-tests show that the equatorward latitudinal limits of introduced alien ranges tend to be at higher latitudes than the equatorward native range latitudinal limits, whilst there is no difference between the poleward latitudinal limits of introduced and native ranges (Table 1a). This results in a smaller latitudinal extent in the introduced than the native ranges (Table 1a).

Similarly, all four metrics of species' native range and established alien ranges are positively correlated (Table 1b, Figure 3a-d): species with their poleward native latitudinal limits at higher latitudes also tend to have their poleward established alien latitudinal limits at higher latitudes, and so on. However, paired t-tests show that the equatorward latitudinal limits of established alien ranges tend to be at higher latitudes than the equatorward native latitudinal limits, while the poleward latitudinal limits of established alien ranges tend to be at lower latitudes than the poleward native latitudinal limits (Table 1b). This translates into smaller latitudinal extents in the established alien than the native ranges, but no difference in the mid-latitudes of established alien and native ranges (Table $1 \mathrm{~b}$ ).

As expected, all four metrics of species' introduced range and established alien ranges are positively correlated (Table 1c, Figure 4ad). However, paired $t$-tests show that the equatorward latitudinal limits of introduced ranges tend to be at lower latitudes than the equatorward latitudinal limits of the established alien ranges, while the poleward latitudinal limits of the introduced ranges tend to be at higher latitudes than the poleward latitudinal limits of the established alien ranges (Table 1c). This translates into larger absolute latitudinal extents for the introduced ranges than the established alien ranges, but no difference in the mid-latitudes of introduced and established alien ranges (Table 1c). The differences between native and established alien latitudinal extents are greater than between native and introduced alien latitudinal extents, as indicated by the larger $t$ statistic for the former (Table 1a-c; mean absolute latitudinal extent
TABLE 1 The relationship across alien bird species $(n=355)$ between the latitudinal extent, equatorward latitudinal limit, midlatitude and poleward latitudinal limit of (a) the introduced alien range and native range, (b) the established alien range and native range and (c) the introduced alien range and established alien range

$\begin{array}{ll}\text { Pearson's } & \text { Paired } t \text {-test } \\ \text { correlation } & \text { 't' statistic }\end{array}$

a) Introduced alien range and native range

$\begin{array}{llc}\text { Latitudinal extent } & 0.27^{* * *} & -4.74^{* * *} \\ \text { Equatorward latitudinal limit } & 0.50^{* * *} & 5.11^{* * *} \\ \text { Mid-latitude } & 0.59^{* * *} & 1.28 \\ \text { Poleward latitudinal limit } & 0.48^{* * *} & -1.92\end{array}$

b) Established alien range and native range

$\begin{array}{llc}\text { Latitudinal extent } & 0.25^{* * *} & -13.35^{* * *} \\ \text { Equatorward latitudinal limit } & 0.54^{* * *} & 11.49^{* * *} \\ \text { Mid-latitude } & 0.63^{* * *} & 1.60 \\ \text { Poleward latitudinal limit } & 0.53^{* * *} & -6.40^{* * *}\end{array}$

c) Introduced alien range and established alien range

$\begin{array}{lll}\text { Latitudinal extent } & 0.75^{* * *} & 13.16^{* * *} \\ \text { Equatorward latitudinal limit } & 0.79^{* * *} & -9.75^{* * *} \\ \text { Mid-latitude } & 0.88^{* * *} & -0.66 \\ \text { Poleward latitudinal limit } & 0.86^{* * *} & 8.43^{* * *}\end{array}$

${ }^{*} p<.05$

${ }^{* *} p<.01$.

${ }^{* * *} p<.001$.

for native ranges: $29^{\circ}$; introduced ranges: $25^{\circ}$; established ranges: $17^{\circ}$ ). See Figure S1 in Appendix 1 in the Supporting Information for the frequency distributions of the introduced and established latitudinal range extents for alien bird species.

\section{DISCUSSION}

Through the process of biological invasion, humans have recast the distributions of numerous species, producing a large-scale natural experiment with the potential to inform about the processes determining native species distributions and concomitant macroecological patterns (Sax, Gaines, \& Stachowicz, 2005). However, before inferences can be made about the influence of natural processes on alien species distributions, we need to account for the influence of the recasting processes. Here, we have built on earlier studies of latitudinal patterns in the richness and geographic range sizes of alien bird species (Guo et al., 2012; Sax, 2001) with the key innovations that the analyses are global in scope, with a wider range of species (355 species compared to 147 in Guo et al., 2012), and most importantly, with the incorporation of data on the latitudes where species were initially introduced. We show that knowledge of latitude of introduction is of fundamental importance in interpreting latitudinal patterns in the richness and geographic range sizes of alien bird species.

Alien bird species richness increases from the poles to the edges of the tropics in the Northern Hemisphere (Figure 1a), but within 
FIGURE 2 The relationship between (a) the absolute lowest (equatorward) latitude of an alien bird species' introduced alien range and the absolute lowest (equatorward) latitude of its native range; (b) the absolute highest (poleward) latitude of an alien bird species' introduced alien range and the absolute highest (poleward) latitude of its native range; (c) the absolute latitudinal midpoint of an alien bird species' introduced alien range and the absolute latitudinal midpoint of its native range; (d) the absolute latitudinal extent of an alien bird species' introduced alien range and the absolute latitudinal extent of its native range. The jitter function in $R$ was used to add noise to the values to enable the density of points to be visualized, with a one to one line in each plot. The same data presented as sunflower plots are included as Figures S2a-d in Appendix S1. $n=355$ (a)

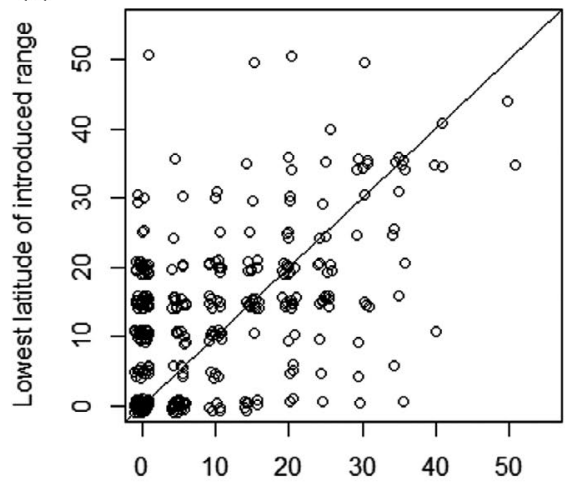

Lowest latitude of native range

(c)

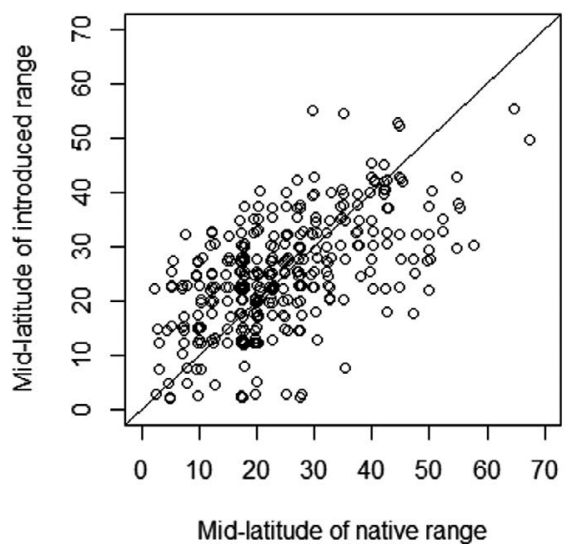

(b)

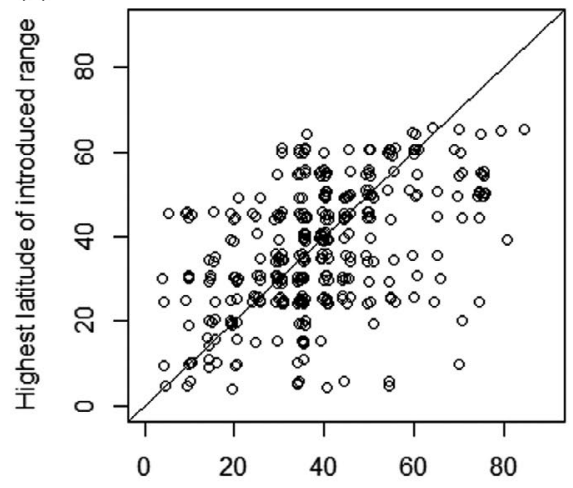

Highest latitude of native range

(d)

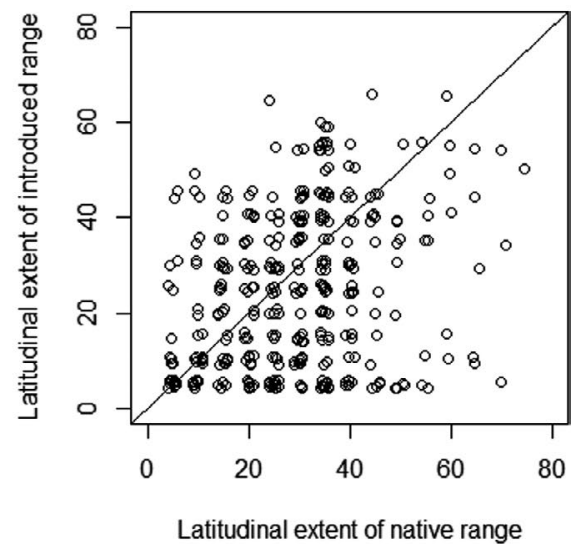

the tropics then decreases towards the equator, with a similar trend in the Southern Hemisphere (Figure 1b). Introductions of alien bird species show similar latitudinal patterns (Figure 1a,b,e,f). The highest values of both introduced and established alien species richness are between 15 and $30^{\circ} \mathrm{N}$ (Figure 1), coinciding with the geographic locations of the Hawaiian Islands, Florida, the Caribbean islands, the UAE, Hong Kong and Taiwan, where many bird species have been introduced, and have subsequently established (Dyer, Cassey, et al., 2017). The two lesser peaks in the Southern Hemisphere between $15-25^{\circ} \mathrm{S}$ and $30-45^{\circ} \mathrm{S}$, coincide with the Mascarene Islands, and New Zealand and southeast Australia respectively. The peak just north of the equator between 0 and $5^{\circ} \mathrm{N}$ is driven primarily by introductions in Singapore.

Our finding that, at the global scale, alien bird species richness increases from the poles to the tropics in both hemispheres but attains relatively low levels throughout the tropics (Figure 1a,b) is the same pattern identified by Sax (2001) within North America. Sax (2001) proposed that this pattern was due to abiotic factors in the temperate zone (reduced energy availability, climatic variation, colder temperatures: Kaufman, 1995; MacArthur, 1972), whereas the lower alien bird richness found in the tropics was a result of biotic resistance (predation, competition, parasitism and disease: Dobzhansky, 1950). However, incorporating data on the total numbers of alien species introduced at different latitudes (established species and failures) shows that the latitudinal patterns of introduced and established alien species richness are very similar in shape (Figure 1a,b), with latitudes that have more established alien bird species also having more species introduced in total (and thus more that have failed). This suggests that although environmental factors may explain some of the variability in alien species richness at any given latitude (Dyer, Cassey, et al., 2017; Stohlgren et al., 2006), latitudinal patterns of established alien bird species richness are largely driven simply by where species have been introduced.

Despite the congruence in latitudinal patterns of introduced and established alien bird species richness, there is nevertheless variation in the number of established species relative to the number introduced at different latitudes, at least in the Southern Hemisphere: alien bird species are in general more likely to have established populations nearer the equator (the increase towards the poles is due to a small number of very successful wide-ranging species that have spread to latitudes where there were very few introductions; Figure 1c,d). This pattern may arise because individual populations are more likely to establish nearer the equator, because more populations have been introduced at lower latitudes (with no necessary variation in establishment success per population across latitudes), or because species are more likely to have spread to those latitudes having been introduced elsewhere. While it is not possible entirely to disentangle these explanations, Blackburn et al. (2018) found that in general, established alien bird 
(a)

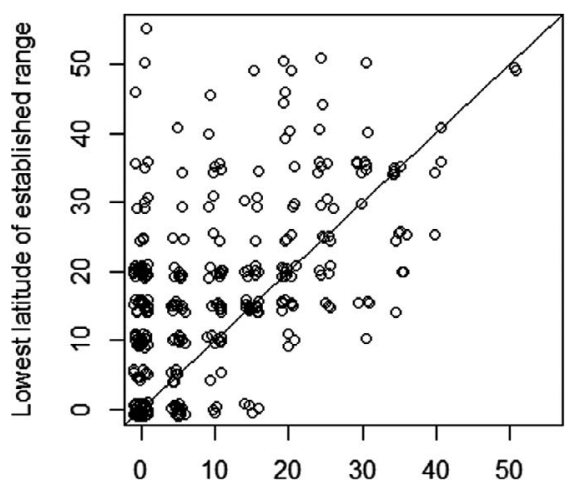

Lowest latitude of native range

(c)

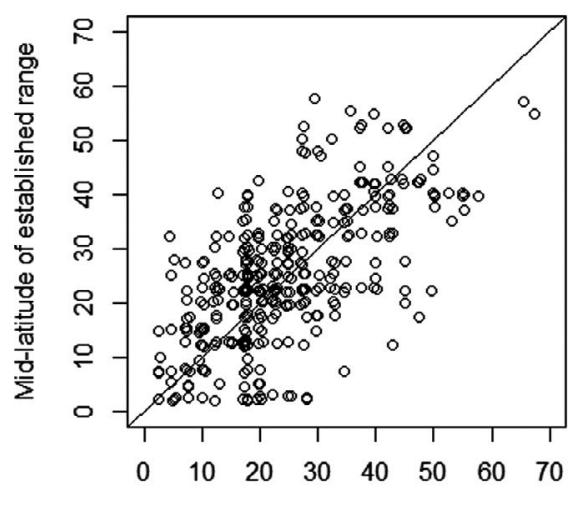

Mid-latitude of native range (b)
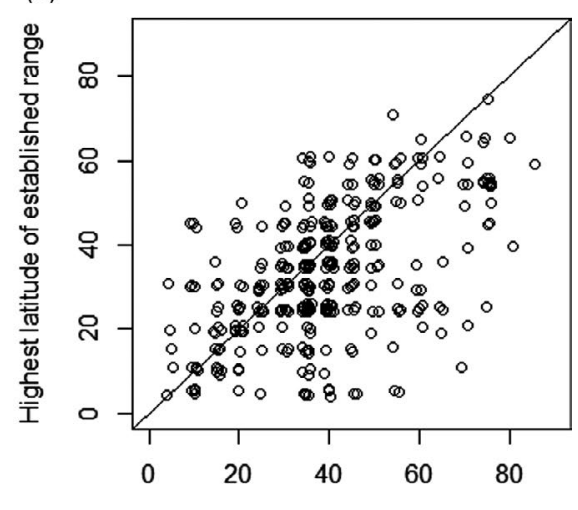

Highest latitude of native range

(d)

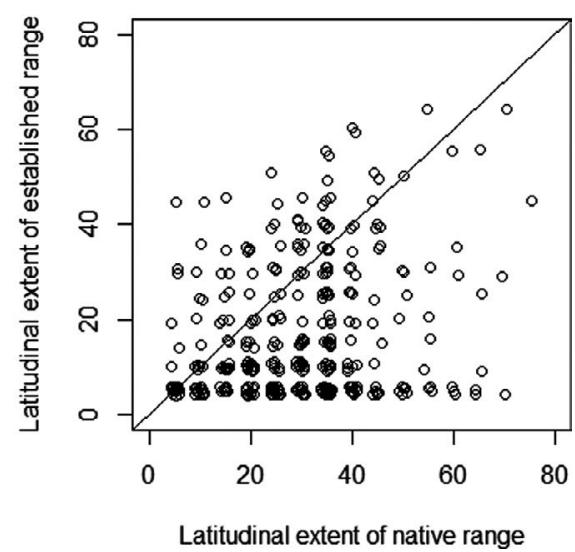

FIGURE 3 The interspecific

relationship between (a) the absolute lowest (equatorward) latitude of an alien bird species' established alien range and the absolute lowest (equatorward) latitude of its native range; (b) the absolute highest (poleward) latitude of an alien bird species' established alien range and the absolute highest (poleward) latitude of its native range; (c) the absolute latitudinal midpoint of an alien bird species' established alien range and the absolute latitudinal midpoint of its native range; (d) the absolute latitudinal extent of an alien bird species' established alien range and the absolute latitudinal extent of its native range. The jitter function in $R$ was used to add noise to the values to enable the density of points to be visualized, with a one to one line in each plot. The same data presented as sunflower plots are included as Figures S3a-d in Appendix S1. $n=355$ species showed little tendency to spread far beyond the latitudes of their introduction. Our results also contradict previous studies that have suggested that the low prevalence of alien bird species in the tropics is because of intrinsic features of the environment there, and in particular biotic resistance (Guo et al., 2012; Sax, 2001). Rather, fewer species were introduced at low latitudes (Figure 1a,b), but a higher proportion of introduced species persist (either through establishment or spread) at those latitudes. These findings are in better alignment with recent results suggesting that a lack of temperature extremes and high precipitation contribute to high alien species richness, while biotic resistance (at least as measured by native bird species richness) does not (Dyer, Cassey, et al., 2017).

The mean total latitudinal extents (a measure of geographic range size) of established alien bird species ranges increase with latitude poleward of the tropics (Figure 1e,f), consistent with both Rapoport's rule (Stevens, 1989) and variation in the size of native bird ranges (Blackburn \& Gaston, 1996; Orme et al., 2006). Our results also broadly conform to the variation in alien bird range size observed by Sax (2001) in North America, outside the tropics at least. However, unlike Sax, we found alien latitudinal range extents to be uniformly small in the tropics. Sax's (2001) analysis of latitudinal extents was confined to those alien birds introduced to mainland North America, and he explained the pattern by the status of most of the tropical mainland species as human commensals, i.e. those that inhabit anthropogenic environments and as such have broad alien ranges. Our analysis is global, including a larger number of species, and more importantly incorporating many alien species with restricted island populations in the tropics. The suggestion by Sax (2001) that large tropical mainland alien ranges are a result of a few wide-ranging species is supported by Dyer, Cassey, et al. (2017), so it would seem that the inclusion of islands in this analysis may explain why the results in Sax (2001) differ from the global patterns found here.

Analyses at the species level demonstrate variation in both the extents and positions of introduced and established alien latitudinal ranges relative to each other, and relative to their native latitudinal ranges. The upper (poleward) latitudinal limits of species' alien and native ranges are positively correlated, as too are the lower (equatorward) latitudinal limits (Table 1b, Figure 3a-d), in concordance with the findings of Guo et al. (2012): species found at high latitudes in their native ranges also tend to be found at high latitudes in their alien ranges, and vice versa for the lower latitudinal range limits (Figure 3). However, in general the equatorward latitudinal limits of the established alien range are positioned at higher latitudes than for the native range, while the poleward latitudinal limits of the established alien range at lower latitudes than for the native range: this means that species have narrower latitudinal extents in their established alien than native ranges (Table 1b; see also Dyer et al., 2016, for alien range size). These narrower 
FIGURE 4 The interspecific relationship between (a) the absolute lowest (equatorward) latitude of an alien bird species' established alien range and the absolute lowest (equatorward) latitude of its introduced range; (b) the absolute highest (poleward) latitude of an alien bird species' established alien range and the absolute highest (poleward) latitude of its introduced range; (c) the absolute latitudinal midpoint of an alien bird species' established alien range and the absolute latitudinal midpoint of its introduced range; (d) the absolute latitudinal extent of an alien bird species' established alien range and the absolute latitudinal extent of its introduced range. The jitter function in $R$ was used to add noise to the values to enable the density of points to be visualized, with a one to one line in each plot. The same data presented as sunflower plots are included as Figures S4a-d in Appendix S1. $n=355$ (a)

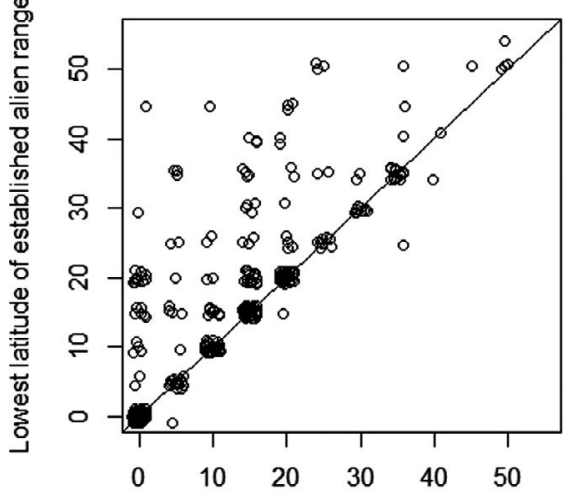

Lowest latitude of introduced range

(c)

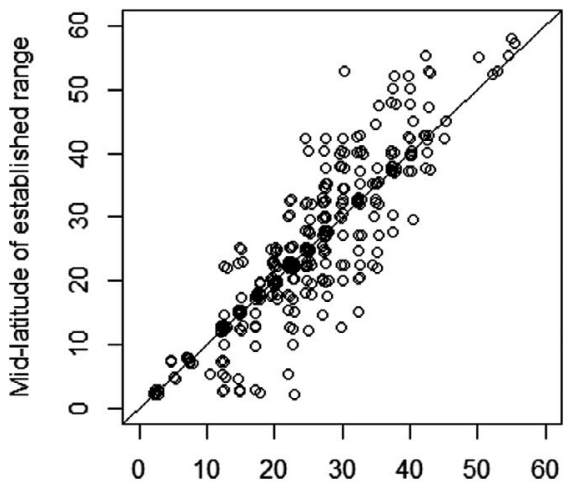

Mid-latitude of introduced range (b)

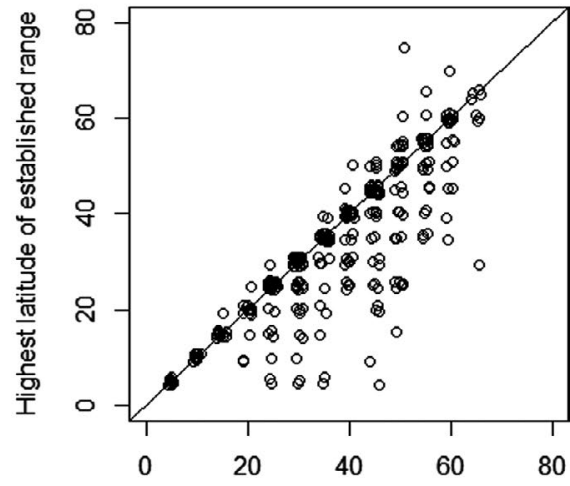

Highest latitude of introduced range

(d)

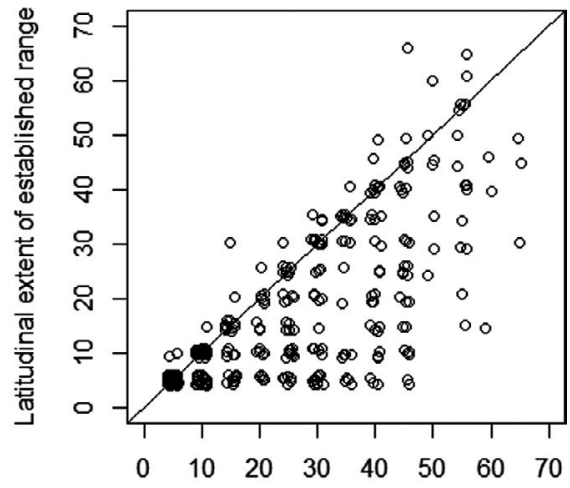

Latitudinal extent of introduced range established alien latitudinal extents reflect where species have been introduced, as most species also have narrower introduced than native latitudinal range extents (Table 1a, Figure $2 a-d$ ), and most species also have narrower established than introduced latitudinal range extents (Table 1c, Figure $4 a-d$ ). Our results therefore provide evidence of range contraction after introduction, with introduced alien ranges having higher poleward latitudinal limits and lower equatorward latitudinal limits than those of the established ranges (Table 1c). Overall, alien bird species are more likely to be introduced within the latitudinal confines of their native ranges, and are more likely to contract away from the more extreme latitudes to which they were introduced (although this should not be interpreted as meaning that introduction events at less extreme latitudes (for the species) are more likely to successfully establish, as this pattern would also be expected with random establishment success due to the use of the Stevens' method (Stevens, 1989) for calculating latitudinal extents). However, these patterns of introduction and contraction result in no differences, across bird species, in the latitudinal midpoints of the introduced, established or native ranges.

Although our study is the first to account for patterns of introduction in analysing latitudinal variation in the richness and latitudinal extents of alien species, certain caveats nevertheless remain. The species analysed are likely to be at different stages of their alien range expansion (Blackburn et al., 2009), and many (or most) may spread beyond their currently recorded established alien ranges. The ranges of some alien species may yet contract or go extinct. The number of recorded introductions may be influenced by higher or lower recording effort in certain regions, influencing apparent patterns of range contraction and position - albeit that birds tend to be relatively well-recorded, especially in temperate zones. The method used to calculate latitudinal range (Stevens method; Stevens, 1989) has the disadvantage that the mean latitudinal range extents for different bands are not independent, with bands that are closer together sharing a higher proportion of the same species (and therefore the same range extents; Gaston, Blackburn, \& Spicer, 1998; Letcher \& Harvey, 1994). However, this method was deemed the most suitable for use with alien bird distributions, as the alternative 'midpoint method' (Rohde, Heap, \& Heap, 1993), would be uninterpretable in cases where the species has spatially disjunct populations (which is the case for many alien bird species). One should not read too much into the significance of the trends in Figure 1 as a result, although the trends themselves are still interpretable.

Many studies of invasion ecology assume that the opportunity for biological invasions is similar across regions. However, as we have shown here, this is not always the case. The latitudinal patterns apparent in alien bird species distributions are in part a result of where species are introduced to, but there is also variation in the likelihood of alien species persistence with latitude, and relative to the latitudinal distribution of the native range. Hence, whilst there 
may be intrinsic differences in the ability of species to extend their latitudinal limits, and differences in the inherent invasibility of specific locations and latitudes, human influence is likely also to be a key factor determining the number of alien species found at any particular latitude.

\section{ACKNOWLEDGEMENTS}

We thank Frances Davis, Victoria Franks, Rebecca Herdson, Elizabeth Jones, Mark Parnell and Fiona Spooner for assistance in compiling the GAVIA database. This study was partly funded by the Leverhulme Trust (grants RF/2/RFG/2010/0016 and RPG-2015392; E.E.D and T.M.B), with additional support from a UCL IMPACT studentship (10989; E.E.D.), and from a King Saud University Distinguished Scientist Research Fellowship (T.M.B., D.W.R., E.E.D.).

\section{DATA AVAILABILITY STATEMENT}

The data that support the findings of this study, first published by Dyer, Redding, et al. (2017), are stored online in a Figshare data repository (http://dx.doi.org/10.6084/m9.figshare.4234850).

\section{ORCID}

Ellie E. Dyer (iD https://orcid.org/0000-0001-5331-4490

David W. Redding (D) https://orcid.org/0000-0001-8615-1798

Phillip Cassey (iD https://orcid.org/0000-0002-2626-0172

Ben Collen iD https://orcid.org/0000-0003-2564-4243

Tim M. Blackburn (iD https://orcid.org/0000-0003-0152-2663

\section{REFERENCES}

Araújo, M. B., Nogúes-Bravo, D., Diniz-Filho, J. A. F., Haywood, A. M., Valdes, P. J., \& Rahbek, C. (2008). Quaternary climate changes explain diversity among reptiles and amphibians. Ecography, 31, 8-15. https://doi.org/10.1111/j.2007.0906-7590.05318.x

Arrhenius, O. (1921). Species and area. Journal of Ecology, 9, 95-99. https:// doi.org/10.2307/2255763

Blackburn, T. M., \& Gaston, K. J. (1996). Spatial patterns in the geographic range sizes of bird species in the New World. Philosophical Transactions of the Royal Society of London. Series B, Biological Sciences, 351, 897-912.

Blackburn, T. M., Lockwood, J. L., \& Cassey, P. (2009). Avian invasions. Oxford: Oxford University Press.

Blackburn, T. M., Redding, D. W., \& Dyer, E. E. (2018). Bergmann's Rule in alien birds. Ecography, 41, 1-9.

Blanchet, S., Grenouillet, G., Beauchard, O., Tedesco, P. A., Leprieur, F., Dürr, H. H., ... Brosse, S. (2010). Non-native species disrupt the worldwide patterns of freshwater fish body size: Implications for Bergmann's rule. Ecology Letters, 13, 421-431. https://doi. org/10.1111/j.1461-0248.2009.01432.x

Brown, J. H. (1995). Macroecology. Chicago, IL: University of Chicago Press.

Davies, R. G., Orme, C. D. L., Storch, D., Olson, V. A., Thomas, G. H., Ross, S. G., ... Gaston, K. J. (2007). Topography, energy and the global distribution of bird species richness. Proceedings of the Royal Society of London. Series B: Biological Sciences, 274, 1189-1197.

del Hoyo, J., Elliott, A., Sargatal, J., Christie, D. A., \& de Juana, E. (Eds.). (2018). Handbook of the birds of the world alive. Barcelona: Lynx Edicions. Retrieved from http://www.hbw.com/

Dobzhansky, T. (1950). Evolution in the tropics. American Scientist, 38, 209-221.
Dowle, E. J., Morgan-Richards, M., \& Trewick, S. A. (2013). Molecular evolution and the latitudinal biodiversity gradient. Heredity, 110(6), 501-510. https://doi.org/10.1038/hdy.2013.4

Dyer, E. E., Cassey, P., Redding, D. W., Collen, B., Franks, V., Gaston, K. J., ... Blackburn, T. M. (2017). The global distribution and drivers of alien bird species richness. PLoS Biology, 15, e2000942. https://doi. org/10.1371/journal.pbio.2000942

Dyer, E. E., Franks, V., Cassey, P., Collen, B., Cope, R. C., Jones, K. E., ... Blackburn, T. M. (2016). A global analysis of the determinants of alien geographical range size in birds. Global Ecology and Biogeography, 25, 1346-1355. https://doi.org/10.1111/geb.12496

Dyer, E. E., Redding, D. W., \& Blackburn, T. M. (2017). The Global Avian Invasions Atlas, a database of alien bird distributions worldwide. Scientific Data, 4, 170041. https://doi.org/10.1038/sdata.2017.41

ESRI. (2018). ArcGIS desktop: Release 10.6. Redlands, CA: Environmental Systems Research Institute.

Fischer, A. G. (1960). Latitudinal variations in organic diversity. Evolution, 14, 64-81. https://doi.org/10.1111/j.1558-5646.1960.tb03057.x

France, R. (1992). The North American latitudinal gradient in species richness and geographical range of freshwater crayfish and amphipods. The American Naturalist, 139, 342-354. https://doi. org/10.1086/285330

Gaston, K. J., Blackburn, T. M., \& Spicer, J. I. (1998). Rapoport's rule: Time for an epitaph? Trends in Ecology \& Evolution, 13, 70-74. https://doi. org/10.1016/S0169-5347(97)01236-6

Gillman, L. N., \& Wright, S. D. (2014). Species richness and evolutionary speed: The influence of temperature, water and area. Journal of Biogeography, 41, 39-51. https://doi.org/10.1111/jbi.12173

Gillman, L. N., Wright, S. D., Cusens, J., McBride, P. D., Malhi, Y., \& Whittaker, R. J. (2015). Latitude and productivity. Global Ecology and Biogeography, 24, 107-117.

Guo, Q., Sax, D. F., Qian, H., \& Early, R. (2012). Latitudinal shifts of introduced species: Possible causes and implications. Biological Invasions, 14, 547-556. https://doi.org/10.1007/s10530-011-0094-8

Hawkins, B. A., Field, R., Cornell, H. V., Currie, D. J., Guégan, J.-F., Kaufman, D. M., ... Turner, J. R. G. (2003). Energy, water, and broadscale geographic patterns of species richness. Ecology, 84, 31053117. https://doi.org/10.1890/03-8006

Jansson, R. (2003). Global patterns in endemism explained by past climatic change. Proceedings of the Royal Society of London. Series B: Biological Sciences, 270(1515), 583-590.

Kaufman, D. M. (1995). Diversity if New World mammals: Universality of the latitudinal gradient of species and bauplans. Journal of Mammalogy, 76, 322-334.

Lemon, J. (2006). Plotrix: A package in the red light district of R. R-News, 6(4), 8-12.

Letcher, A. J., \& Harvey, P. H. (1994). Variation in geographical range size among mammals of the Palearctic. The American Naturalist, 144, 3042. https://doi.org/10.1086/285659

Lever, C. (2005). Naturalised Birds of the World. London: T \& A D Poyser.

Long, J. L. (1981). Introduced birds of the world. Newton Abbot, UK: David $\&$ Charles.

MacArthur, R. H. (1972). Geographic ecology: Patterns in the distribution of species. New York: Harper \& Row.

Orme, C. D. L., Davies, R. G., Burgess, M., Eigenbrod, F., Pickup, N., Olson, V. A., ... Owens, I. P. F. (2005). Global hotspots of species richness are not congruent with endemism or threat. Nature, 436, 1016-1019. https://doi.org/10.1038/nature03850

Orme, C. D. L., Davies, R. G., Olson, V. A., Thomas, G. H., Ding, T.-S., Rasmussen, P. C., ... Gaston, K. J. (2006). Global patterns of geographic range size in birds. PLoS Biology, 4, 1276-1283. https://doi. org/10.1371/journal.pbio.0040208

Pianka, E. R. (1966). Latitudinal gradients in species diversity: A review of the concepts. The American Naturalist, 100, 33-46. 
Pianka, E. R. (1989). Latitudinal gradients in species diversity. Trends in Ecology \& Evolution, 4, 223. https://doi. org/10.1016/0169-5347(89)90163-8

Pither, J. (2003). Climate tolerance and interspecific variation in geographic range size. Proceedings of the Royal Society of London. Series B: Biological Sciences, 270, 475-481.

Pysek, P., Jarosik, V., Hulme, P. E., Kuhn, I., Wild, J., Arianoutsou, M., ... Winter, M. (2010). Disentangling the role of environmental and human pressures on biological invasions across Europe. Proceedings of the National Academy of Science of the United States of America, 107, 12157-12162. https://doi.org/10.1073/pnas.1002314107

R Core Team. (2018). R: A language and environment for statistical computing. Vienna, Austria: R Foundation for Statistical Computing. Retrieved from https://www.R-project.org/

Rapoport, E. H. (1982). Areography: Geographical strategies of species. Oxford: Pergamon.

Rohde, K. (1992). Latitudinal gradients in species diversity: The search for the primary cause. Oikos, 65, 514-527. https://doi.org/10.2307/ 3545569

Rohde, K., Heap, M., \& Heap, D. (1993). Rapoport's rule does not apply to marine teleosts and cannot explain latitudinal gradients in species richness. The American Naturalist, 142, 1-16. https://doi. org $/ 10.1086 / 285526$

Roy, K., Jablonski, D., \& Valentine, J. W. (1994). Eastern Pacific molluscan provinces and latitudinal diversity gradient: No evidence for Rapoport's Rule. Proceedings of the National Academy of Science of the United States of America, 91, 8871-8874. https://doi.org/10.1073/pnas.91.19.8871

Sax, D. F. (2001). Latitudinal gradients and geographic ranges of exotic species: Implications for biogeography. Journal of Biogeography, 28, 139-150. https://doi.org/10.1046/j.1365-2699.2001.00536.x

Sax, D. F., Gaines, S. D., \& Stachowicz, J. J. (2005). Exotic species: A source of insight into ecology, evolution, and biogeography. Sunderland, MA: Academic Press.

Smith, F. D., May, R. M., \& Harvey, P. H. (1994). Geographical ranges of Australian mammals. The Journal of Animal Ecology, 63, 441-450. https://doi.org/10.2307/5561

Stevens, G. C. (1989). The latitudinal gradient in geographical range: How so many species co-exist in the tropics. The American Naturalist, 133 , 240-256. https://doi.org/10.1086/284913

Stevens, G. C. (1996). Extending Rapoport's rule to Pacific marine fishes. Journal of Biogeography, 23, 149-154. https://doi. org/10.1046/j.1365-2699.1996.00977.x

Stohlgren, T. J., Barnett, D., Flather, C., Fuller, P., Peterjohn, B., Kartesz, J., \& Master, L. L. (2006). Species richness and patterns of invasion in plants, birds, and fishes in the United States. Biological Invasions, 8, 427-447. https://doi.org/10.1007/s10530-005-6422-0

Tomašových, A., Jablonski, D., Berke, S. K., Krug, A. Z., \& Valentine, J. W. (2015). Nonlinear thermal gradients shape broad-scale patterns in geographic range size and can reverse Rapoport's rule. Global Ecology and Biogeography, 24, 157-167. https://doi.org/10.1111/geb.12242 von Humboldt, A. (1850). Views of nature: or contemplations on the sublime phenomena of creation; with scientific illustrations (E. C. Otte \& H. G. Bohn, Trans.). London, UK: Henry G. Bohn.

Whittaker, R. J., Willis, K. J., \& Field, R. (2003). Climate-energetic explanations of diversity: A macroscopic perspective. In T. M. Blackburn \& K. J. Gaston (Eds.), Macroecology: Concepts and consequences (pp. 107-129). Oxford: Blackwell Science.

Wright, S. D., Gillman, L. N., Ross, H. A., \& Keeling, D. J. (2010). Energy and the tempo of evolution in amphibians. Global Ecology and Biogeography, 19, 733-740. https://doi.org/10.1111/j.1466-8238.2010.00549.x

Wright, S., Keeling, J., \& Gillman, L. (2006). The road from Santa Rosalia: A faster tempo of evolution in tropical climates. Proceedings of the National Academy of Sciences of the United States of America, 103, 7718-7722. https://doi.org/10.1073/pnas.0510383103

\section{BIOSKETCH}

Ellie Dyer is a macroecologist currently investigating the determinants of global patterns in alien bird assemblages. Her research interests concern topics in biodiversity, macroecology and conservation. The two research teams involved in this analysis are based in the Centre for Biodiversity and Environment Research (CBER) at University College London (https://www.ucl.ac.uk/ cber) and at the Invasion Science and Wildlife Ecology group at the University of Adelaide (http://www.cassey-invasion-ecolo gy.org). Both have research aims concerning the understanding of global patterns in the distribution of alien species.

Author contributions: E.E.D and T.M.B conceived the ideas; E.E.D collected and analysed the data; and E.E.D and T.M.B led the writing, to which all authors contributed

\section{SUPPORTING INFORMATION}

Additional supporting information may be found online in the Supporting Information section.

How to cite this article: Dyer EE, Redding DW, Cassey P, Collen B, Blackburn TM. Evidence for Rapoport's rule and latitudinal patterns in the global distribution and diversity of alien bird species. J Biogeogr. 2020;00:1-11. https://doi. org/10.1111/jbi.13825 